\title{
Оптическое детектирование спиновой поляризации свободных электронов в полупроводниковых гетероструктурах с пространственным разрешением
}

\author{
О.Е. Терещенко ${ }^{1,2)}$, В.А. Голяшов ${ }^{1,2)}$, В.С. Русецкий ${ }^{1,3)}$, Н.С. Назаров ${ }^{2)}$, \\ А.В. Миронов ${ }^{3)}$ В.В. Аксенов ${ }^{3)}$ \\ ${ }^{I}$ Институт физики полупроводников им. А.В. Ржанова СО РАН, \\ пр. Ак. Лаврентьева, 13, Новосибирск, 630090 \\ ${ }^{2}$ Новосибирский государственный университет, ул. Пирогова, 2, Новосибирск, 630090 \\ ${ }^{3} 3 А О$ «ЭКРАН-ФЭП», ул. Зеленая горка, д.1, Новосибирск, 630060 \\ тел:+7 (383) 330-78-83, эл. почта: teresh@isp.nsc.ru
}

DOI 10.34077/RCSP2019-32

Изучение инжекции свободных спин-поляризованных электронов в полупроводниковые структуры остается сложной технической задачей. Решение данной задачи может позволить создать спин-детектор свободных электронов с пространственным разрешением для использования в современных энергоанализаторах электронов, в частности, в методе фотоэмиссии с угловым разрешением. Предлагаемый тип спин-детектора позволяет измерять три компоненты проекции спина: две компоненты спина в плоскости поверхности, используя тонкий ферромагнитный слой на полупроводнике в качестве спин-фильтра $[1,2]$, и нормальную компоненту, измеряя поляризацию катодолюминесценции (КЛ).

Методом поляризованной катодолюминесценции изучена инжекция спин-поляризованных электронов в вакуумных фотодиодах, в которых источником спин-поляризованных электронов являлся GaAs c отрицательным электронным сродством (ОЭС), а детектором - гетероструктура $\mathrm{AlGaAs} / \mathrm{GaAs} / \mathrm{AlGaAs}$ с квантовыми ямами, также активированная до состояния с ОЭС. Измерена зависимость поляризации электронного пучка от энергии инжектируемых электронов в интервале 0.5-4 эВ, которая удовлетворительно описывается релаксацией спина по механизму ДьяконоваПереля. В области низких кинетических энергий 0.5-0.65 эВ степень поляризации максимальна и не зависела от энергии электронов, что, вероятно, связано с прямым туннелированием спинполяризованных электронов в квантовые ямы. Получена величина асимметрии равная $15 \%$, близкая к теоретической оценке. Впервые измерено пространственное (латеральное) распределение поляризации электронов в сечении пучка путем измерения распределения латеральной интенсивности поляризованной катодолюминесценции. Данный спин-детектор позволит увеличить эффективность измерения спиновой поляризации в $10^{4}$ раз относительно одноканального спиндетектора Мотта.

\section{Лumepamypa}

[1] O.E. Tereshchenko, et al. // J. of Appl. Phys. 109, 113708 (2011).

[2] X. Li, et al. // Appl. Phys. Lett. 105, 052402 (2014). 